ISSN 0819-2642

ISBN 073402598 X

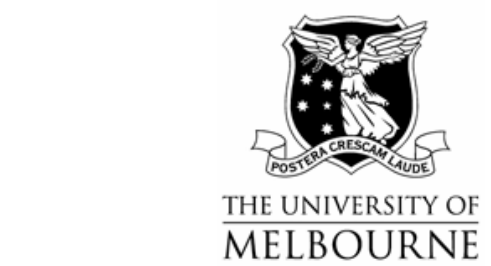

THE UNIVERSITY OF MELBOURNE

DEPARTMENT OF ECONOMICS

RESEARCH PAPER NUMBER 942

JULY 2005

\title{
INVESTMENT DECISIONS AND EMISSIONS REDUCTIONS: RESULTS FROM EXPERIMENTS \\ IN EMISSIONS TRADING
}

\author{
by \\ Lata Gangadharan \\ \& \\ Alex Farrell \\ $\&$ \\ Rachel Croson
}

Department of Economics

The University of Melbourne

Melbourne Victoria 3010

Australia. 
Investment Decisions and Emissions Reductions:

\title{
Results from Experiments in Emissions Trading
}

\author{
Lata Gangadharan \\ University of Melbourne \\ Alex Farrell \\ University of California, Berkeley \\ Rachel Croson \\ The Wharton School \\ University of Pennsylvania
}




\title{
Investment Decisions and Emissions Reductions: \\ Results from Experiments in Emissions Trading
}

\begin{abstract}
Emissions trading is an important regulatory tool in environmental policy making. Unfortunately the effectiveness of these regulations is difficult to measure in the field due to the unavailability of appropriate data. In contrast, experiments in the laboratory can provide guidance to regulators and legislatures about the performance of different market features in emission trading programs. This paper reports on the implementation of three different institutional designs, and presents experimental results investigating important features of emissions trading regimes: the ability to make investments in emissions abatement, ability to bank allowances and a declining emissions cap, both with and without uncertainty. These features are observed in virtually all existing air pollution emissions trading programs currently in place and will almost certainly be part of future applications. Like previous experimental studies of emissions trading, this paper shows that the efficiency gains expected from economic theory emerge observationally. We also show reduced efficiency when permits are bankable due to over-banking and when investments in emissions abatement are possible due to overinvesting. These tendencies do not worsen, however, when emissions caps decline.
\end{abstract}

JEL Classification: Q20, C91

Key Words: Emissions Trading, Investment in Abatement, Banking, Laboratory Experiments 


\section{Introduction}

Over the past several decades, emission trading has evolved from a suggestion by economists to a regulatory tool widely seen as highly successful (Farrell and Lave 2004). Examples include the well-established sulfur dioxide allowance trading program in the United States and the just-emerging $\mathrm{CO}_{2}$ emission reduction credit program in Europe (Carlson et al. 2000; Boemare and Quirion 2002). ${ }^{1}$ Currently, emissions markets protect both human and ecosystem health, and in the process result in billions of dollars changing hands. The application of emissions trading mechanisms will influence many decisions, including both operational (e.g., What fuel to purchase?) and investment choices (e.g., When to purchase abatement technology?). New patterns of investment may be among the most important outcomes of emission trading programs because massive investment in new technologies are likely to be needed to successfully deal with some environmental challenges, such as global warming (Hoffert et al. 2002). Many of these capital investments are irreversible and very long-lived (electric power plants often operate for more than forty years), during which time regulations may change, creating uncertainty about optimal investment strategies. This paper uses an experimental economics approach to evaluate how individuals behave in emissions trading markets with opportunities for investment.

A well-known form of emission trading, and the form used in the experiments described below, is the cap-and-trade system, which, as the name implies, creates a permanent limit on emissions. In this system, the regulator defines the regulated sources and the total amount of pollution that can be emitted during a set period-the "cap." Typically, the cap is set in mass units (e.g., tons), is lower than historical emissions, and declines over time. The regulator creates allowances equal to the size of the cap and then distributes them to the regulated sources-a process called allocation. The regulator then requires regulated firms to surrender emission

\footnotetext{
${ }^{1}$ Similar market-based approaches have been taken for many environmental goals, not just abating air pollution. Examples include individual transferable quotas for fishing rights, tradable development rights for land use, and renewable portfolio standards (Boyd et al. (2003)., Hindsberger et al. (2003)).
} 
allowances equal to their emissions, on a periodic basis. Because the allocation to each firm is smaller than its previous emissions, regulated firms have four basic options: (1) control emissions to exactly match their allocation; (2) under-control and buy allowances to cover their emissions; (3) over-control and then sell their excess; or (4) over-control and bank allowances for use in future years (when even fewer allowances will be allocated). The reason firms might buy or sell allowances is that they often have different emission control costs, or they might change operations so that they need more (or fewer) allowances. Firms with higher costs could save money by under-controlling and buying allowances from those with lower costs, which could make money by over-controlling and selling allowances.

Although emissions trading programs are motivated and justified by micro-economic concepts, there are variations in the specific situations they are called on to regulate, in the goals for the market and thus in the choices of market institutions and program design that must be made by regulators. In this paper we examine the impacts of some of these market institutions and details on the performance of these markets using laboratory methods. A significant literature on the use of laboratory experiments to investigate emissions trading programs has developed over the last decade, summarized in Muller and Mestelman (1998) and Bohm (2003). Theoretical, modeling, and empirical approaches have been employed to evaluate various policy questions associated with emissions trading, but these approaches must either make strong assumptions about firm behavior or utilize the results of relatively scarce examples. Experiments provide useful supplements to field studies in illuminating questions about firm behavior in emissions markets that would be difficult or costly to achieve otherwise. In contrast to empirical analyses, experimental studies allow careful control and measurement of efficiency and other theoretical constructs. In addition, experiments allow researchers to directly test hypotheses and testbed institutional changes that could not be done in the field. ${ }^{2}$

\footnotetext{
${ }^{2}$ Plott and Porter (1996). describe experimental testbedding as a method by which policy is initially implemented in a simple laboratory setting. If the policy does not work, or if it works but is not theoretically understandable then there is no reason to expect it to work in a more complex field setup.
} 
This paper focuses on one methodological issue and three institutional features. In contrast to most of the papers in this area, we use an experimental design that describes emission permits in terms of its impact on production. This design is more intuitive and simpler to understand from the participants' point of view. The three institutional features we examine are: banking of allowances, investment in abatement technology and uncertainty relating to permit allocation. The different rules adopted by the regulators in these markets are crucial choices, not just details. $^{3}$

One particularly important decision is if and how allowances can be saved (or "banked") from one period to another. Previous theoretical and experimental research has argued that banking has the potential to add efficiency by smoothing out the prices particularly in the initial periods when there is a lot of uncertainity about the market (Cronshaw and Brown-Kruse 1999, Godby et al. 1997 and Mestelman et al. 1999, Kling and Rubin 1997), but may need to be managed (Cason and Gangadharan 2005, Rubin 1996, Belanger 1997, Foster and Hahn 1995, Klier et al. 1997). ${ }^{4}$

Another important goal of emissions trading systems is to optimize investment in emissions controlling equipment. Emissions trading helps in managing transitions to loweremission production processes, which often require large, irreversible capital investments (Bohi and Burtraw 1992, Ben-David et al 1999, Fullerton et al. 1997). Emissions trading, banking and investment have a complex relationship. Early investment in controls can produce surplus permits, which provides firms with the opportunity to sell allowances or to bank them for later use, when emissions constraints may be tighter (Bohi and Burtraw 1992, Ellerman 1996, Berman and Bui 1998, Montero and Ellerman 1998). On the other hand, the ability to use allowances to defer an irreversible and potentially useless investment could also be valuable (Dixit and

\footnotetext{
${ }^{3}$ Other researchers have examined additional features of these markets like market power (Godby 1999) and compliance (Murphy and Stranlund 2004).

${ }^{4}$ Cason and Gangadharan, 2005 in particular find that in treatments where subjects are given the option to bank allowances, emissions and non-compliance rates are significantly higher.
} 
Pindyck 1993, Chao and Wilson 1993). The centrality and importance of the investment question to emissions trading motivates us to attempt to introduce the issue into the laboratory.

Few previous studies have examined the impact of investment in abatement technology on emission markets in an experimental framework. Ben-David et al. (1999) provide subjects with a choice of three technologies and examine the impact of firm technological cost hetereogeneity on the operation of the permit market. They find that heterogeneity can lead to reduced trade volume and lower efficiency. Buckley et al. (2004) examine alternative approaches to emissions trading and test the prediction that capacity, emissions and output would be higher under variable baseline and credit trading than under cap and trade trading. Kusakawa and Saijo (2003) find that investment uncertainty could reduce efficiency in emission markets. In this paper we examine, in a simplified setting, whether emission markets encourage optimal investment and the extent to which such investment impacts market efficiencies. In our experiment we make the information about investing in abatement technology public. We find that agents tend to overinvest in abatement equipment in our laboratory markets.

An additional goal for emissions trading markets is to provide an equilibrating mechanism when conditions change. The final market design we test therefore, is the ability of the market to react to uncertainty in the environment (Winebrake et al. 1995, Godby et al. 1997, Chao and Wilson 1993). It has been argued that uncertainty and other factors such as transaction costs have prevented some emissions markets from working in the past (Hahn 1989, Foster and Hahn 1995). Uncertainty comes in many forms, but one that seems especially salient is the potential for ever-tighter environmental regulations in the future. In several of the most notable cases, progressively more stringent standards have been built into emissions markets (Fichthorn 1991, Lents and Leyden 1996, Farrell 1999). Additionally, the outcome from one emissions market can affect another. For example, the introduction of $\mathrm{CO}_{2}$ regulation of some sort in the U.S. could influence the $\mathrm{SO}_{2}$ market because the relative prices for coal and natural gas (which contains much less sulfur than coal) could shift dramatically, reducing the demand for $\mathrm{SO}_{2}$ 
allowances. Although this could be a large effect, it is currently highly uncertain since the debate on $\mathrm{CO}_{2}$ control is nowhere near resolution.

Ben-David et al. (2000) use laboratory techniques to explore the specific effects of uncertainty in tradable permit markets on prices, trading volume, firms' ability to realize cost savings and invest in abatement technology. They focus on two types of uncertainty: uncertainty regarding the time at which the permit allocation will be reduced and uncertainty regarding the magnitude of the reduction and find that in the presence of uncertainty firms adopt a 'wait and see’ approach towards investment. In several papers by Godby et al. (1997 and 1998), and one by Cronshaw and Brown-Kruse (1999) the impact of uncertainty and banking is examined, and while banking is found to have price stabilization features, it also has efficiency costs in this context. In addition, these studies showed that there was a tendency for participants to bank more allowances under uncertainty than would have been the case in equilibrium (overbanking). Cason et al. (1999) introduce declines in the allocation of emissions allowances over time in their experiment. They find relatively low efficiencies in these markets when there is uncertainty, but suggest that the experimental design may have contributed to this problem. Cason and Gangadharan (2005) introduce uncertainty in the form of random correlated and uncorrelated shocks to the abatement and emissions target specified by the firms, which could occur due to unexpectedly low production or due to superior abatement equipment performance. They find that prices are more volatile after the emission shocks however banking helps in smoothing out the price volatility arising from the uncertainty over emissions.

Our experimental design compares market outcomes when emission standards are constant to outcomes when they will change in the future. In some treatments, subjects face a certain decline in allowances and in others the decline is uncertain. While overbanking is still observed in these treatments, it is less than in certain decline treatments.

This paper extends the research efforts described above in two ways, first by developing a new experimental design to improve data collection and second, by developing experimental treatments to examine real-world interactions of investment, banking and uncertainty. The 
different experimental design was motivated by concerns that increasingly complex treatments could overwhelm participants in emissions market experiments, who have limited time and attention to spend on the exercise. In addition, existing experiments tend to overemphasize the emissions market at the expense of the underlying product market. Firms in emissions markets are primarily motivated by forces in their product markets (e.g. electricity), and are beginning to see emissions allowances as just another input with its own markets just like other inputs to production, such as fuel (Farrell 1999). Thus we sought to describe the emissions market in terms of its impact on the production market in a way that was context-free and largely masked the fact that environmental policy was involved, while still conducting an experiment in emissions trading. The resulting design is described in the next section. We find that this method though simpler, yields similar results as the other papers in the field.

Often papers in this literature examine one institutional feature in isolation. In the field however market participants and regulators are interested in the performance of emission markets in the presence of these features simultaneously. This paper contributes to this literature by studying the interaction of banking and investment and banking and uncertainty and their impact on market outcomes. For example, we find that in sessions where we allow for investment and banking the proportion of permits "over banked" is reduced relative to treatments where we allow only banking. This suggests that overbanking may be less of a problem in the world (where investments are presumably possible) than in the laboratory (where they frequently are not).

The rest of the paper is organized as follows. Section 2 describes the experimental design, section 3 outlines the theoretical predictions. Section 4 presents the results and Section 5 concludes.

\section{Methodology}

The experimental economics methodology has proven to be a powerful tool in advancing our understanding of how people make decisions in economic or strategic environments. Our 
experimental design and procedures were informed by previous research not only in the area of emissions trading but also in the area of experimental markets more generally. ${ }^{5}$

\subsection{Experimental Design}

While previous experiments have examined the impact of emissions trading in terms of abatement, holding the output (e.g. the quantity of electricity produced) fixed and examining the impact of markets on pollution emitted, in our experiment we approach the question from the opposite direction. The experimental design we use holds the amount of pollution produced fixed and varies the quantity of output produced. We do this by fixing the number of allowances available, but varying the earnings each firm receives from using an allowance to simulate greater production possibilities by cleaner plants. The advantage of this approach is that the market can be described in a way that is particularly accessible to participants, and in a way that was free from the context of environmental policy. This approach can be motivated by considering an electricity sector that contains both very clean (e.g. gas-fired or renewable) and heterogeneously dirty (e.g. coal-fired) generation and assuming that the latter have lower marginal production costs. The participants in our experiment represent only the latter, and work within the constraints of the emissions cap (masked in our design) to maximize profit by producing electricity and trading allowances. If demand does not change, any increase in electricity generated by the participants is assumed to be offset by less electricity being generated by the very clean units that do not participate in the emissions trading market.

Theoretically these different approaches should yield identical results. Both measure the extent to which emissions permit trading improves the efficiency with which output is produced. However, empirically they may not. Thus a methodological contribution of our paper is to provide a robustness check on efficiency and other results reported by previous experiments.

${ }^{5}$ Experiments have been used to study decision-making in areas as diverse as markets, the voluntary provision of public goods, voting and bidding in online auctions. Davis and Holt (1994) and Kagel and Roth (1995) provide excellent overviews of the methodology and research produced in this area. 
Participants in our experiment trade in a double auction market for a series of periods called markets. The double auction trading institution is widely used; all parties have equal bargaining power, it performs efficiently even with a small number of traders (Smith 1962, Smith and Williams 1992), and it best captures the naturally-occuring emissions trading markets. Subjects were given a set of instructions that were read aloud to create common knowledge (appendix A contains sample instructions). In these instructions subjects were told that they represent a firm producing a good called a widget. To the subject, a widget was conceived of as a physical good; however for purposes of this discussion, a widget should be thought of as the amount of output (e.g. electricity) a given firm can produce while releasing one unit of pollutants. Firms are heterogeneous in our experiments, thus the amount of output a firm can produce (the value of the widget) while emitting one unit of pollutants is higher for cleaner firms and lower for dirtier firms.

This heterogeneity is captured in the experiment by assigning some firms a higher profit per widget than others (those are the cleaner firms who are producing more output per unit of pollutant released). The conceptual model behind this heterogeneity involves a competitive market for output, where each unit of output is sold for a normalized price of $\$ 1$. For each unit of pollutant released, cleaner firms produce more output than dirtier firms. Thus for each unit of pollutant released, cleaner firms earn more than dirtier firms. So the cleanest firm's profit from a widget (that is, from the amount of output it is able to produce while releasing one unit of pollutant) was $\$ 10$ while the dirtiest firm’s profit was only $\$ 5$.

Once the basic idea of widget sales is understood, participants are then told their capacity for widgets (corresponding to their capacity for output production). They are also told that the government requires firms to have a license before they can produce widgets. Firms receive some licenses from the government, and can buy extra licenses or sell all or some of their given licenses on that market. These licenses correspond to emissions allowances or permits which are licenses to release one unit of pollutant. 
Table 1 describes the experimental parameters we use. For the present discussion we will focus only on the parameters in bold text. We constructed six types of firms, differing in their cleanliness and size. The first row of Table 1 describes the number of permits per period the government allocates to each type of firm. We assumed that government allocations of permits to firms would follow the typical practice of a grandfathering policy, allocating more pollution permits to the dirtiest firms. The second row describes the value of the permit to each firm. The third row describes each firm's capacity in terms of permits, while the last row translates that capacity into our assumptions about capacity in production of electricity. We assume that dirtier firms have higher capacity for electricity production (with some variations to allow the numbers to divide evenly).

$<$ Table 1 about here $>$

Participants in the experiment are told they may not sell short (sell more permits than they have) and that unused permits will expire at the end of the period. They are told there will be more than one period, but not told exactly the number of repetitions to expect (in order to avoid endgame effects). Subjects were compensated based on their firm's profitability, including both profits from production and profits from trading permits.

\subsection{Measuring Market Efficiency}

We will examine two types of market efficiency measures. The first is a measure of the trading efficiency of the permit market in its role as a market. That is, how much of the available surplus from trading is realized? This measure will be the one typically used in market experiments (Holt 1995).

For example, imagine a market with six firms in it, one of each type from Table 1. If the market is efficient, dirty firms who value the permits less should sell them to clean firms who value the permits more. This will create gains from trade. However, the cleaner firms should not buy all the permits that dirty firms might be able to offer because the capacity constraints of the clean firms would prevent them from using all available permits (the cleanest firm can only use 5 permits, it is given 1 permit, thus it only demands at most 4 permits, while the dirtiest firm 
has 6 permits to sell). Figure 1 depicts the supply and demand curve from such a market taking these capacity constraints into account. The maximum trading surplus which could be generated is \$270. Our measure of trading efficiency will involve calculating the maximum possible trading surplus for each market, calculating the actual surplus earned from trading, and reporting trading efficiency as the ratio of the two.

$<$ Figure 1 about here $>$

Our second measure of efficiency is a measure of productive efficiency. This measure captures the extent to which electricity is produced in the most efficient manner (by the cleanest firms). For this measure, we will report the number of units of output produced. Remember that while previous papers have held the amount of output produced constant and examined the impact of markets on the amount of pollution released, our experiment does the reverse. Since we control the number of pollution permits released into the economy, reporting pollution produced would not be informative. Instead, we report the amount of output (electricity) produced for a given level of pollution. When cleaner firms are producing (and polluting), the amount of output produced for a given amount of pollution should be higher than when dirtier firms are producing. In addition to reporting the absolute amount of output produced, we will report the fraction of the output produced in this market relative to the amount that would be produced in equilibrium.

\subsection{Treatments}

Since our research was motivated by the effects of market institutions on emissions permit markets and on investment behavior, our experimental design involves comparing prices, trading and production efficiency in treatments representing different market rules, including the possibility for investment in emissions control equipment (which in our design appears as investments in efficiency-enhancing capital) and uncertainty about the future supply of permits. The experimental design is presented in Figure 2 below with circles representing the different treatments and lines representing the comparisons of interest. In all treatments, subjects trade in a number of periods, but do not know when the session would end. After each period, we 
randomly choose a number between 1 and 100 and if the number chosen is between 1 and 20 the session would end.

$<$ Figure 2 about here $>$

Trading only (baseline)

The first treatment, baseline, is as described above. Participants trade in the market, then produce given the permits they have and their capacity constraints. Permits expire before the next period. Trading and production efficiency measures are calculated as above. 36 subjects participated, 6 subjects of each type, in this treatment and we collected data from 4 periods.

\section{Banking}

The second treatment, banking, investigates the impact of allowing firms to bank (save) their permits period-to-period. 33 subjects participated in this treatment for 6 periods. This treatment is identical to the baseline with the exception that after the period, firms can choose to use their permits to produce or save them for the next period. In the current experimental context where each period is simply a replication of the one before, the equilibrium prediction is that there should be no banking.

The banking treatments also provide some special challenges for the calculation of trading and production efficiency. To illustrate this difficulty with an example, consider a firm of type 2 with a capacity constraint of seven permits (63 units of electricity). In the first period they are given 2 permits, imagine that they purchase six more (one more permit than they can use given their capacity constraints). They use seven permits for production and bank (save) one. Now, two complications arise.

First, when calculating the trading surplus from the period, how should we assume the firm values that superoptimal permit? Three alternatives suggest themselves. First, the permit could be valued at the value for permits for that firm (in this example \$9), even though it is not being used for production (and indeed, may never be used for production). This alternative overstates the actual trading surplus created, and thus overstates the trading efficiency of the market. Second, the permit could be valued at zero, since it is not being used for production by 
the purchasing firm. This alternative understates the actual trading surplus created, and thus understates the trading efficiency of the market. Finally, the permit could be valued at the price paid (for this option we assume the cheapest permit purchased is the inframarginal one). This would generate zero surplus for the purchaser of the permit (although positive surplus for the seller) and represents a middle ground. We will present all three calculations for the banking treatment to provide the reader with an understanding of how the choice affects reported efficiencies. For the remainder of the treatments, only the third value (based on the market price) will be used.

The second complication involves calculating the next period's equilibrium prediction. Since the extra permit was banked, the market in the next period has an extra unit of supply (and one fewer unit of demand) than the first market did. Thus in all the remaining periods the equilibrium prediction (market price and quantity, theoretical trading surplus and theoretical production surplus) changes from period to period. When reporting trading and production efficiency measures below we will take this into account, recalculating the equilibrium prediction of these measures for each period.

\section{$\underline{\text { Investment }}$}

The third treatment (directly below banking in Figure 2) allows both banking and investment. 28 subjects participated for 6 periods in this treatment. Instructions were the same as the banking treatment with one addition. Firms could choose to spend 80 experimental dollars to make an investment in their plant. Firms which made this investment were assumed to upgrade their plant's equipment, enabling them to produce more electricity for the same amount of pollution emitted. Thus the investment increased their value for a widget. The investment was described in the instructions as a process improvement, increasing their profits for each widget sold. This is one of the first few papers to examine the interaction of investment decisions and market outcomes.

The regular text rows of Table 1 labeled "when investment" denote the impact on each type of firm of making this investment. Notice that the impact of investment is asymmetric; 
dirty firms have much more to gain by upgrading their plant (increasing their electricity production for each unit of pollution released from 5 to 9) while the improvement on the part of clean firms is more modest. In order to retain the (approximate) electricity production capacities in the bottom row, investment also influences the firm's capacity for widgets. Importantly, we are thus assuming that investment increases firm cleanliness but not its capacity for making electricity.

Optimal investment behavior is straightforward to calculate. First, since investment is a one-time decision yielding future benefits, if a firm is going to invest it should do so in the first period. Additionally, the cost of investment was set strategically so that if the market were at equilibrium only a subset of firms would choose to invest. Finally, information about investment decisions was announced publicly during each period of the experiment.

Just as the existence of banking leads us to rethink our measure of trading efficiency, the investment option leads us to extend our measure of productive efficiency. In particular, when investment is available, the total possible productive efficiency (that is, the maximum amount of electricity that can be produced by this market for a given level of pollution) will vary by the number of firms investing in emission controls. If more firms invest, plants overall will be cleaner and the market as a whole can produce more electricity for a given level of pollution.

We can adjust our benchmark of expected productive efficiency to incorporate changes caused by investment in two ways. First, we can calculate the total possible productive efficiency we would expect under equilibrium investment behavior. We would then compare the actual productive efficiency to this benchmark. The disadvantage of this benchmark measure is that it makes these markets look more efficient than they are (especially since it does not account for the cost of the investment). The advantage is that presents a more accurate comparison between the treatments. When investment is an option, the market produces much more electricity for a given level of pollution than when investment is not an option.

Second, we can calculate the benchmark of total possible productive efficiency given actual (not equilibrium) investment behavior. This more appropriately captures the concept of 
productive efficiency by answering the question: for a given distribution of cleanliness of firms, are they producing efficiently? The disadvantage is that the comparison between the treatments is less clear. We may end up with a lower productive efficiency measure in this treatment than in another, even though this market is more productively efficient (producing more electricity per unit of pollution released). We will report both measures in our analysis below.

\section{Certain Decline}

The fourth and fifth treatments (to the right of banking in Figure 2) investigate the impact of decreasing the number of pollution permits in the marketplace, as happened (or will happen) in many emissions markets. The fourth treatment examines the case where this decrease is known (as in Cason et al. 1999) and the fifth, where it is unknown. In both treatments, the decline in permit allocations is as shown in Table 1, in the regular text row titled "when declining.” In these treatments, banking is permitted but there is no investment option, as can be seen in the experimental design of Figure 2.

In the fourth treatment, this decline is anticipated and known to the subjects. Instructions are as in the banking treatment, but subjects are told that after the second period all permit allocations from the government will decline. Subjects are told how their own permit allocations will change, as well as the change in total permits available in the market. They are not told, however, how the distribution of permits will change.

The anticipated decline in permit allocations provides a reason for saving (banking) permits. In particular, if subjects had rational expectations, exactly enough permits would be banked in order to make the profit from selling or using a permit the same in all periods, thus predicting the same market prices over time. 31 subjects participated in 5 periods in this treatment.

\section{Uncertain Decline}

In the fifth treatment, uncertain decline, subjects are told only that the number of permits they receive could decline after the second period (and that the total number of permits in the market will decline) but not by exactly how much. They were told that they would never receive 
less than $50 \%$ of their original allocation. ${ }^{6}$ This treatment (with 40 subjects participating in 5 periods) represents perhaps the most realistic case of capturing market uncertainty in emissions permit markets since there is a tendency towards higher and higher environmental standards. The addition of uncertainty makes theoretical benchmarks for this treatment difficult, as each subject's optimal response depends on their beliefs about the future drop in permits. That said, we can make some qualitative predictions describing equilibrium behavior, which we do in the next subsection.

\section{Theoretical Benchmarks}

Table 2 describes the theoretical benchmarks we have calculated and will be using to compare with outcomes for each treatment. The table incorporates factors like the number of experimental subjects who participated in each treatment as well as the number of permits offered and saved (banked) in each period. For the baseline treatment, this number of permits is constant for all periods, for the other treatments, the number of permits available depends on the number that were saved (banked) by the subjects, and thus changes period to period.

$<$ Table 2 about here $>$

The table also describes the equilibrium price and quantity in each treatment in each period. As mentioned above, the market equilibrium in all treatments but the baseline change in each period, due to banking activities by the players. As in all discrete market settings, these numbers are often ranges rather than point predictions. The equilibrium trading efficiency is the maximum trading efficiency possible given the number and distribution of permits in each treatment in each period. Our results will report actual trading efficiency (surplus created by trades) as a percentage of this optimal amount.

The final three lines of the table describe equilibrium productive efficiency. These are the number of units of electricity which could have been produced given the permits used (the amount of pollution released) had only the most efficient firms produced, taking into account

\footnotetext{
${ }^{6}$ In the treatments in Ben-David et al. (2000), the reduction in the number of permits was $35 \%$ or $45 \%$ of the original allocation.
} 
capacity constraints. The second and third measures of productive efficiency are calculated for the investment treatment. They involve an identical calculation either for the optimal investment behavior (described below) or for the observed investment behavior.

The remaining theoretical benchmark involves optimal investment behavior. The parameters were set such that only type 4 firms had the incentive to invest in cleaning up their plants. Appendix A provides a description of the equilibrium. Intuitively, firms of type 1 and 2 are not improved enough by the investment to make it worth paying for (they earn at most an extra \$55 worth of profit over the (expected) five periods, not recovering their \$80 investment expenditure). Firms of type 5 and 6 earn more by selling their endowment of permits than they could by investing and producing (the increase in their profits from investing and producing is at most \$30 over the expected five periods). Firms of type 3 earn more by investing and producing than by not investing and still producing, but not enough to overcome the cost of investing (earning $\$ 50$ over the expected five periods versus $\$ 80$ to invest). Only firms of type 4 earn enough by investing to overcome the costs ( $\$ 135$ over the expected five periods versus $\$ 80$ to invest). Thus we assume firms of type 4 invest and all others do not in our calculation of the measure of benchmark productive efficiency.

With our benchmark results available we now turn to the experimental results in each of the treatments.

\section{Results}

We report the results for each treatment comparing how the outcomes measures perform with respect to the theoretical predictions. Then we compare the treatments with each other to examine if some design features yield higher efficiencies absolutely and relative to their equilibrium predictions.

\section{Trading only (baseline)}

Table 3 depicts the experimental results from the baseline treatment, in each period and averaged over the periods. Average price was a bit higher, and quantity a bit lower, than 
predicted by equilibrium analysis. This suggests that subjects did not make all the paretoimproving trades that they could have made. Consistent with this observation, we see suboptimal surplus earned from trading. However, productive efficiency was relatively high.

In the theoretical benchmark, the three dirtiest firm types should sell their permits to the three cleanest firm types. Closer inspection of the data indicate that these dirtiest firms were not entirely selling (although they were indeed net suppliers). In particular, the percentage of the permits used for production by the three dirtiest firm types in each period was $40 \%, 27 \%$, $24 \%$ and $20 \%$. That this proportion decreases over time suggests that these firms were learning that they earned more by selling their permits than by keeping them and producing. Figure 3 depicts the percentage of permits used by each type of firm in all of the treatments, along with the distribution which would be expected under full productive efficiency.

$<$ Table 3 about here $>$

As in other experiments, results from this baseline treatment show high production efficiency compared to the theoretical benchmark. The next subsections investigate institutional designs which may further improve efficiency of the market.

\section{Banking}

Table 4 depicts the experimental results from the banking treatment, in each period and averaged over the periods. As in the baseline condition, the average price is higher than the equilibrium prediction and the quantity lower. However, in contrast to the baseline, this is not due to dirty firms choosing to produce inefficiently. Instead it is due to superoptimal banking of permits. Since the supply and demand of permits remained constant in this treatment in equilibrium no permits should be banked. Instead we observed more permits banked than used in all periods except the last (rows three and four of Table 4). This excessive banking made our measure of trading surplus extremely sensitive to how we valued these banked permits. The third measure (the one we use for the remainder of the treatments) values permits purchased for the sole purpose of banking at their cost, does not incorporate those transactions into the measure of trading surplus and is thus most comparable with previous and future treatments. Using this 
measure we see no significant difference in trading efficiency between this and the baseline treatment (probability value of a pairwise t-test which determines the difference in means, across treatments $=0.30){ }^{7}$ However, we see significantly higher productive efficiency measures in this than in the baseline treatment (probability value $=0.05$ ). The addition of an alternative use for permits (saving them to be sold in the future) seems to have prevented the dirtiest firms from using their permits for production. This can be seen graphically in Figure 3 by comparing the percentage of permits used by the dirtiest firms in the baseline and banking treatments.

$<$ Table 4 about here $>$

These results suggest that the institution of banking permits does not hurt and may help trading and productive efficiency. However, they also indicate a potential for overbanking, which suggests that permits with shorter lifespan might be more effective than those that are valid indefinitely.

\section{$\underline{\text { Investment }}$}

In our next treatment we examined the efficiency of the emissions market when firms had the opportunity to invest in cleaning up their plant and when permits were bankable. First, we continue to see the overbanking of permits as in the previous treatment. However, we also observe significant overinvestment. As mentioned before, the parameters were set such that only type 4 firms had the incentive to invest in cleaning up their plants. Instead we observed firms of all types investing; 17 out of 28 firms invested (61\%) all but two at the first opportunity. This overinvestment is reflected in higher prices (and lower quantities) than predicted by equilibrium, as well as in lower trading efficiencies than in previous treatments (t-tests and the Wilcoxon's rank-sum tests show that trading efficiency is significantly lower in this treatment as compared to the banking and the baseline treatments), reported in Table 5. Subjects in this treatment achieved higher productive efficiencies due to the increased investment. The productive efficiencies in smaller font incorporate the costs of investing, when actual investments are taken into account

\footnotetext{
${ }^{7}$ We also conducted non-parametric Wilcoxon Rank-Sum tests of differences in distributions across treatments. The results are similar to the t-tests.
} 
the productive efficiencies are lower in this treatment than in the banking treatment, however the difference is not statistically significant. The lower productive efficiency could be in part driven by the shorter number of periods the firms had in order to recoup their investment expenditures.

$<$ Table 5 about here $>$

These results suggest that allowing firms to invest in cleaning up their plants has two effects. First, the proportion of permits banked decreases somewhat, although it does not decrease to its equilibrium level of zero. Second, firms overinvest, yielding high productive efficiencies but spending more than is socially optimal on investment. Dirtier firms invest in cleaning up, then produce in place of firms which were originally clean, so that investment costs become socially wasteful. This result highlights a possible danger with tradable emissions permits that should be closely observed; when firms invest to clean up their plants, bankable permits may have a greater negative impact than previously thought. Notice that this overinvestment is observed even though firms are not competing in the marketplace on price or faced with nonlinear returns to scale.

\section{Certain Decline}

Unlike the previous treatments, in the two treatments with declining permits banking can (and indeed should) occur in equilibrium. In particular, subjects should bank enough permits to keep the price constant over time. In this treatment, however, we again saw overbanking (as seen in Table 2 when equilibrium prices fall between periods 2 and 3 rather than staying constant). As before, this overbanking caused low trading efficiencies when firms saved their permits instead of trading them (t-tests and Wilcoxon tests show that trading efficiency is significantly lower than the baseline and the banking treatment but not significantly different from the banking and investment treatment). However, productive efficiencies were reasonable in this treatment and not significantly different as compared to other treatments, suggesting that production was primarily done by the cleanest firms.

$<$ Table 6 about here> 
These results suggest that having the permits issued decline over time in a known fashion will not harm productive efficiency and will harm trading efficiency only in as much as we observe superoptimal banking.

\section{Uncertain Decline}

Table 7 shows results from the uncertain declining treatment, they are quite similar to those in certain decline. Subjects exhibt overbanking, but not as much as in the banking treatment. Trading efficiencies were low due to this problem (significantly lower than the baseline and the banking treatment, but not different from the banking and investment and the certain decline treatment), but production efficiencies were high (though not significantly higher than the other treatments). These results suggest that having the permits issued decline over time in a unknown fashion is not significantly different than having them decline in a known manner, although both hurt trading efficiency their effects on productive efficiency are minimal.

$<$ Table 7 about here $>$

Table 8 presents results from simple ordinary least squares regression models that pool the data across all treatments and compare average prices (relative to price benchmarks in individual treatments), trading and productive efficiency. The models have four treatment dummies and period as the independent variables. The estimates show that trading efficiency is lower in all the treatments as compared to the baseline, however productive efficiency is not significantly different across the treatments. The pairwise t-tests discussed above also confirm this. The deviation of price from treatment benchmarks is significantly higher in treatments with banking, and certain and uncertain decline of permits as compared to the baseline treatment. This could be due to subjects not being able to adjust easily to the change in conditions each period (for example the number of permits banked in the previous period).

$<$ Table 8 about here $>$

\section{Discussion}

This paper uses laboratory evidence to examine the interaction between banking, investment, and decline of permits in an emissions trading setting. We examine price and 
efficiency in the different treatments where subjects are allowed to bank permits, invest in abatement technology or face uncertainty in permit allocation. We employ the concept of trading efficiency (which measures how much of the available surplus from trading is realized in the permit market) and productive efficiency (which measures the fraction of output, like electricity, produced in the experiments relative to the amount produced in equilibrium) to understand how subjects behave in different treatments. This paper also introduces a methodological advance. Our results obtained from employing a relatively unusual experimental design, where we describe the emissions market in terms of its impact on the production market in order to provide a context-free experiment, are largely consistent with results from other experiments.

We find that in treatments when banking is available, subjects overbank, that is they save more permits than they would as compared to theoretical predictions. When investment in cleaning up emissions is possible, subjects overinvest, again leading to cleaner production but reduced efficiency. The proportion of permits overbanked is reduced however relative to sessions where investment is not possible. When the number of permits available declines over time, agents continue to overbank, although less so relative to the equilibrium amount.

These results are not simply experimentally interesting. We see similar outcomes in actual pollution permit markets. For example, overbanking of allowances and overinvestment in abatement technology have been argued to be some of the reasons for lower allowance prices in Phase 1 of the $\mathrm{SO}_{2}$ market (Ellerman et al. 2000) ${ }^{8}$. Regulators in the field are currently creating designs to provide the right incentive schemes to discourage overbanking. For example, the Ozone Transport Commission in the Eastern U.S. included restrictions on the aggregate level of banking (Farrell et al. 1999). In particular, if the total amount of banked emissions by all sources exceeds 10 percent of the total allowable emissions for the year, a 2-for-1 discount is applied to the use of the extra banked allowances, i.e. value of the banked permits fall.

\footnotetext{
${ }^{8}$ Overinvestment was triggered by among other things, a general underestimation of the extent to which declines in rail rates for transporting low-sulfur Western coal would drive down the price of coal and hence reduce the need for abatement to meet the Phase I target.
} 
A central result of the paper is that when individuals are given an opportunity to invest in abatement technology they can use it more than is optimal. Given that this investment crowds out other, potentially more productive investment, this is a somewhat undesirable outcome. The results from our experiment show that if firms with low abatement values, decide to invest in abatement technology they could (in effect) be spending money to clean up, then need to produce in the market to recover these costs, taking production away from cleaner firms. This could be socially suboptimal. An additional reason why individuals could be overinvesting in this experiment is that the investment decision is public information. There could therefore be some peer group influence being exerted in the experiment, with individual firms overestimating the impact of investment. Since the emissions market itself is the central motivator of the control equipment investment decision, it seems clear that we need a deeper understanding of how the market institutions affect these investment decisions.

Future research in this area could, for example, use information as a treatment variable to examine if individuals are more willing to adopt new technology when they see others adopting it. Information about others' abatement decisions could be guiding investment decisions, even in situations where there is no uncertainty. Including the issue of uncertainty in this framework would make this more of a problem, with individuals thinking of other's investment decisions as signals that the regulations are going to tighten and that permits would decline soon. This interaction between investment, banking, uncertainty and information would be interesting to explore.

In summary, this paper makes a number of contributions. Methodologically, we develop a simpler mechanism for use in emissions trading experiments. In our baseline condition we replicate results from previous experiments using this simpler mechanism. Substantively, we explore the impact of a series of market institutions on efficiency, including banking of permits, investment in emissions abatement technology and declining permit allocations. This investigation illuminates both theoretically interesting and practically relevant issues in market design and implementation. 
Table 1: Experimental Parameters

\begin{tabular}{|c|c|c|c|c|c|c|}
\hline & $\begin{array}{l}\text { Type } 1 \\
\text { (cleanest) }\end{array}$ & Type 2 & Type 3 & Type 4 & Type 5 & $\begin{array}{l}\text { Type } 6 \\
\text { (dirtiest) }\end{array}$ \\
\hline \# permits & 1 & 2 & 3 & 4 & 5 & 6 \\
\hline when declining & 1 & 2 & 3 & 2 & 3 & 4 \\
\hline $\begin{array}{l}\text { Value of } \\
\text { permit* }\end{array}$ & $\$ 10$ & $\$ 9$ & $\$ 8$ & $\$ 7$ & $\$ 6$ & $\$ 5$ \\
\hline when investment & $\$ 11$ & $\$ 11$ & $\$ 10$ & $\$ 10$ & $\$ 9$ & $\$ 9$ \\
\hline $\begin{array}{l}\text { capacity } \\
\text { in permits }\end{array}$ & 5 & 7 & 9 & 11 & 13 & 15 \\
\hline when investment & 5 & 6 & 7 & 8 & 9 & 8 \\
\hline $\begin{array}{l}\text { production } \\
\text { capacity }\end{array}$ & 50 units & 63 units & 72 units & 77 units & 78 units & 75 units \\
\hline when investment & 55 units & 66 units & 70 units & 80 units & 81 units & 72 units \\
\hline
\end{tabular}

*number of units of electricity which can be produced by using up one permit (releasing the amount of pollution allowed by one permit), all units assumed to be sold at the market price of $\$ 1$. 
Figure 1: Supply/Demand for Permits

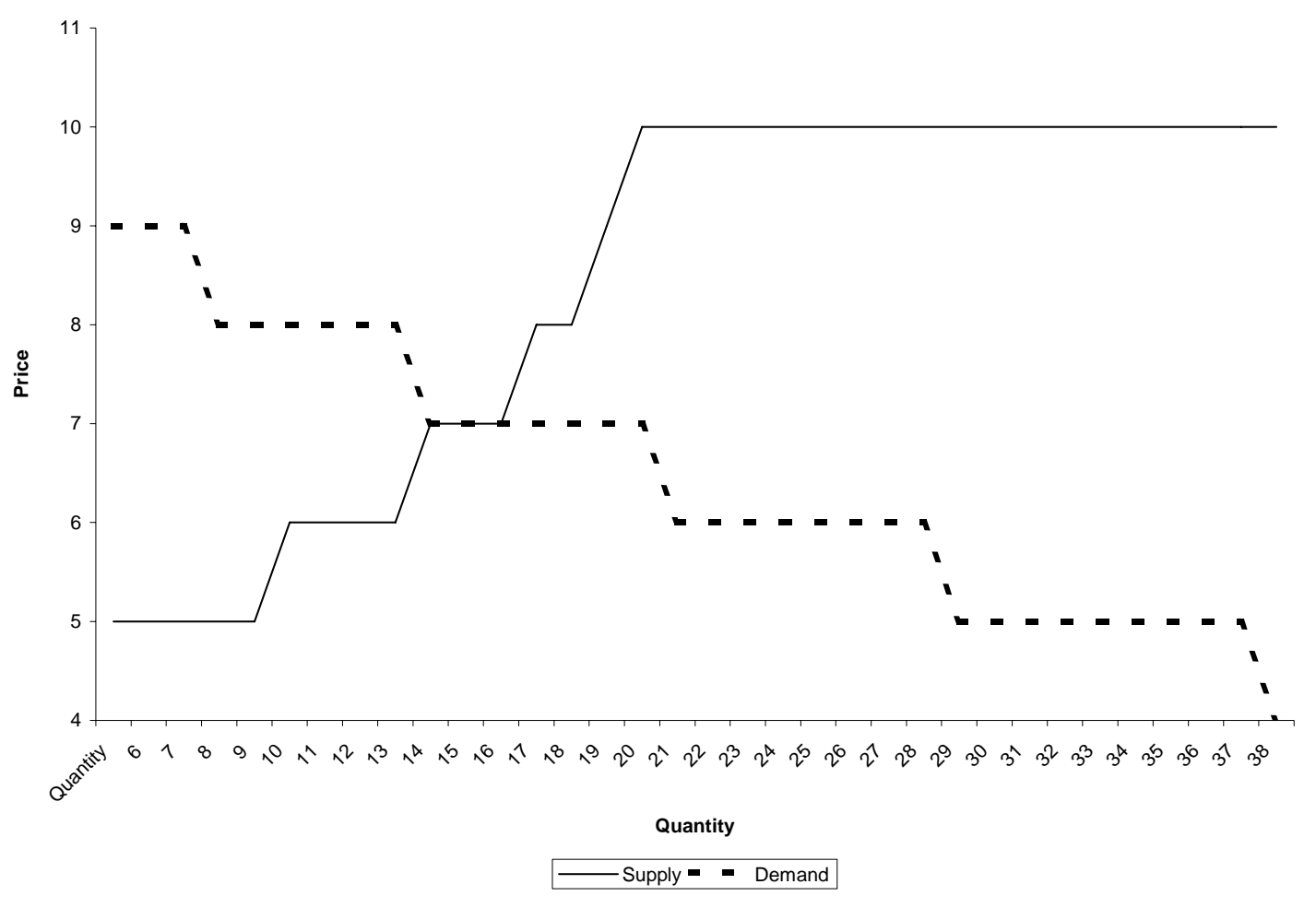


Figure 2: Experimental Design

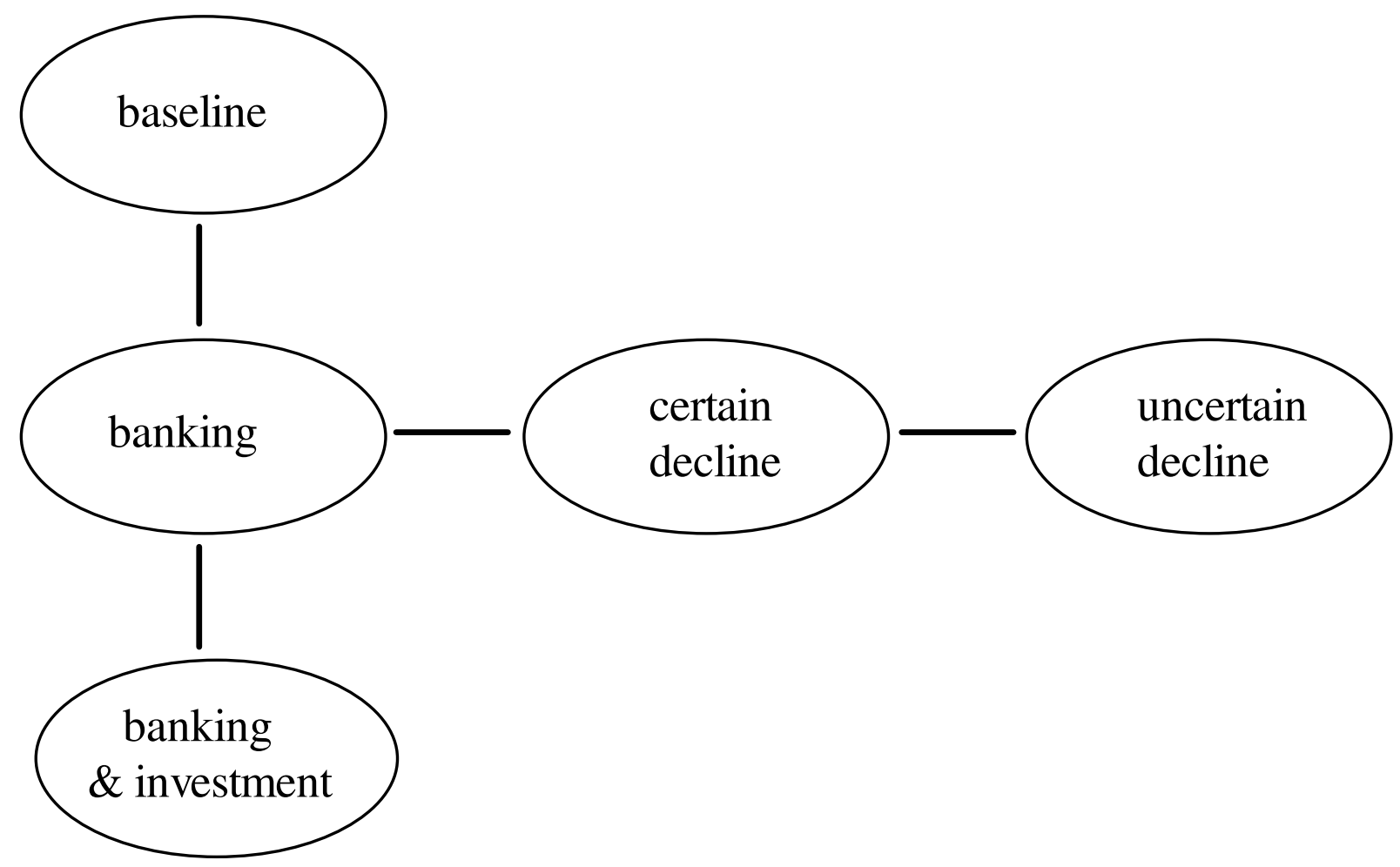


Table 2: Equilibrium Predictions in the Treatments

\begin{tabular}{|c|c|c|c|c|c|}
\hline & Baseline & Banking & Banking \& Investment & Certain Decline & Uncertain Decline \\
\hline Number of Players & 36 & 33 & 28 & 31 & 40 \\
\hline Number of Permits & 126 & 116, 172, 219, 258, 270, 256 & $102,146,151,156,165,170$ & 111, 153, 175, 176, 182 & 138, 193, 216, 190, 200 \\
\hline Benchmark (eq) quantity & 90 & $79-85,70-77,44-81,34-45,37-44,51-54$ & $71-73,44-51,52-56,49-54,40-45,44-45$ & $71-81,74-77,64-75,50-70,47-69$ & 95-99, 76-95, 94-97, 86-90, 70-83 \\
\hline Benchmark (eq) price & $\$ 7-\$ 8$ & $\$ 7, \$ 6, \$ 6, \$ 6, \$ 6, \$ 6$ & $\$ 8, \$ 8, \$ 8, \$ 8, \$ 8, \$ 8$ & $\$ 7, \$ 7, \$ 6, \$ 6, \$ 6$ & $\$ 7, \$ 7, \$ 7, \$ 7, \$ 7$ \\
\hline Benchmark (eq) trading efficiency & 270 & $249,197,147,61,53,88$ & $205,169,204,180,147,147$ & $225,194,136,118,114$ & $285,210,228,179,166$ \\
\hline Benchmark productive efficiency (0) & 1110 & $585,646,715,931,1119,1868$ & & $627,531,699,659,1272$ & $781,773,949,829,1418$ \\
\hline Benchmark productive efficiency (1) & & & $529,905,905,873,905,1217$ & & \\
\hline Benchmark productive efficiency (2) & & & $529,973,978,942,978,1592$ & & \\
\hline
\end{tabular}

Benchmark productive efficiency (0) \# of units of electricity which could have been produced given \# of permits used

Benchmark productive efficiency (1) \# of units of electricity which could have been produced given \# of permits used with optimal investment

Benchmark productive efficiency (2) \# of units of electricity which could have been produced given \# of permits used with observed investment 
Table 3: Results from Baseline Treatment

\begin{tabular}{|l|cccc|c|}
\hline \multicolumn{1}{l}{ Average Price } & 1 & 2 & 3 & 4 & Avg \\
\cline { 2 - 6 } & $\$ 8.25$ & $\$ 7.82$ & $\$ 7.75$ & $\$ 8.32$ & $\$ 8.04$ \\
Quantity & 63 & 67 & 77 & 75 & 70.50 \\
Trading Surplus Earned & 150 & 186 & 207 & 213 & 189 \\
\% Trading Efficiency & $56 \%$ & $69 \%$ & $77 \%$ & $79 \%$ & $70 \%$ \\
& & & & & \\
Units Output Produced & 981 & 1026 & 1054 & 1053 & 1029 \\
$\%$ Productive Efficiency & $88 \%$ & $92 \%$ & $95 \%$ & $95 \%$ & $93 \%$ \\
\hline
\end{tabular}


Figure 3: Percentage Permit Use by Type

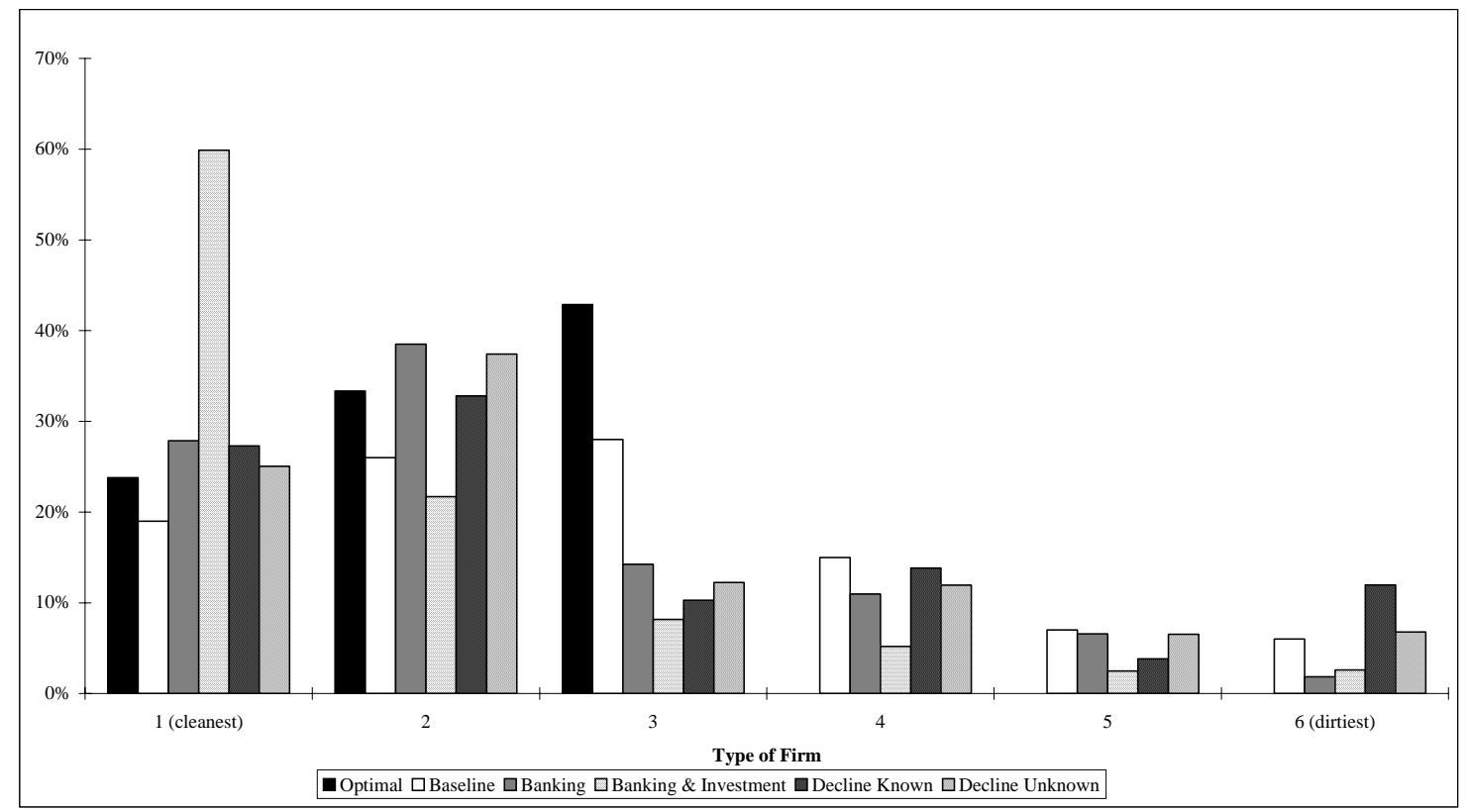


Table 4: Results from Banking Treatment

\begin{tabular}{|l|cccccc|c|}
\hline \multicolumn{1}{|c}{1} & 2 & 3 & 4 & 5 & 6 & Avg \\
\cline { 2 - 8 } & $\$ 8.14$ & $\$ 8.31$ & $\$ 8.13$ & $\$ 7.84$ & $\$ 7.20$ & $\$ 5.43$ & $\$ 7.51$ \\
Quantity & 83 & 70 & 92 & 97 & 70 & 70 & 80.33 \\
\# Permits Used & 60 & 69 & 77 & 104 & 130 & 249 & 114.83 \\
\# Permits Banked & 56 & 103 & 142 & 154 & 140 & 7 & 100.33 \\
& & & & & & & \\
Trading Surplus Earned (1) & 200 & 198 & 290 & 246 & 151 & 59 & 190.67 \\
\% Trading Efficiency & $80 \%$ & $101 \%$ & $197 \%$ & $403 \%$ & $285 \%$ & $67 \%$ & $189 \%$ \\
& & & & & & & \\
Trading Surplus Earned (2) & 100 & -48 & -231 & -252 & -104 & 8 & -87.83 \\
\% Trading Efficiency & $40 \%$ & $-24 \%$ & $-157 \%$ & $-413 \%$ & $-196 \%$ & $9 \%$ & $-124 \%$ \\
& & & & & & & \\
Trading Surplus Earned (3) & 150 & 92 & 65 & 51 & 40 & 43 & 73.50 \\
\% Trading Efficiency & $60 \%$ & $47 \%$ & $44 \%$ & $84 \%$ & $75 \%$ & $49 \%$ & $60 \%$ \\
Units Output Produced & 535 & 638 & 701 & 915 & 1098 & 1838 & 954.17 \\
\% Productive Efficiency & $91 \%$ & $99 \%$ & $98 \%$ & $98 \%$ & $98 \%$ & $98 \%$ & $97 \%$ \\
\hline
\end{tabular}


Table 5: Results from Banking and Investment Treatment

\begin{tabular}{|l|cccccc|c|}
\hline \multicolumn{1}{|c}{1} & 2 & 3 & 4 & 5 & 6 & Avg \\
\cline { 2 - 8 } & $\$ 6.99$ & $\$ 8.67$ & $\$ 9.44$ & $\$ 9.39$ & $\$ 9.16$ & $\$ 8.31$ & $\$ 8.66$ \\
Quantity & 74 & 52 & 57 & 66 & 61 & 50 & 60.00 \\
\# Permits Used & 58 & 97 & 97 & 93 & 97 & 168 & 101.67 \\
\# Permits Banked & 44 & 49 & 54 & 63 & 68 & 2 & 46.67 \\
& & & & & & & \\
Trading Surplus Earned (3) & 142 & 32 & 51 & 17 & 10 & 102 & 59.00 \\
\% Trading Efficiency & $69 \%$ & $19 \%$ & $25 \%$ & $9 \%$ & $7 \%$ & $69 \%$ & $33 \%$ \\
& & & & & & & \\
Units Output Produced & 509 & 912 & 932 & 920 & 962 & 1571 & 967.67 \\
\% Productive Efficiency (1) & $96 \%$ & $101 \%$ & $103 \%$ & $105 \%$ & $106 \%$ & $129 \%$ & $107 \%$ \\
\% PE (1)- Opt. Inv. costs & $36 \%$ & $101 \%$ & $103 \%$ & $105 \%$ & $106 \%$ & $129 \%$ & $97 \%$ \\
\% Productive Efficiency (2) & $96 \%$ & $94 \%$ & $95 \%$ & $98 \%$ & $98 \%$ & $99 \%$ & $97 \%$ \\
\% PE (2)- Act. Inv. costs & $-131 \%$ & $86 \%$ & $95 \%$ & $89 \%$ & $98 \%$ & $99 \%$ & $56 \%$ \\
\hline
\end{tabular}


Table 6: Results from Certain Decline Treatment

\begin{tabular}{|l|ccccc|c|}
\hline \multirow{2}{*}{ Average Price } & 1 & 2 & 3 & 4 & 5 & Avg \\
\cline { 2 - 7 } & $\$ 7.75$ & $\$ 8.41$ & $\$ 8.42$ & $\$ 8.37$ & $\$ 8.17$ & $\$ 8.22$ \\
Qu Permits Used & 66 & 71 & 65 & 51 & 80 & 66.60 \\
\# Permits Banked & 69 & 57 & 78 & 73 & 157 & 86.80 \\
& 42 & 96 & 97 & 103 & 25 & 72.60 \\
Trading Surplus Earned (3) & 100 & 49 & 33 & 26 & 34 & 48.40 \\
\% Trading Efficiency & $44 \%$ & $25 \%$ & $24 \%$ & $22 \%$ & $30 \%$ & $29 \%$ \\
& & & & & & \\
Units Output Produced & 545 & 508 & 657 & 619 & 1257 & 717.20 \\
\% Productive Efficiency & $87 \%$ & $96 \%$ & $94 \%$ & $94 \%$ & $99 \%$ & $94 \%$ \\
\hline
\end{tabular}


Table 7: Results from Uncertain Decline Treatment

\begin{tabular}{|l|ccccc|c|}
\hline \multicolumn{1}{|c}{1} & 2 & 3 & 4 & 5 & Avg \\
\cline { 2 - 7 } & $\$ 7.33$ & $\$ 8.00$ & $\$ 8.13$ & $\$ 8.25$ & $\$ 8.17$ & $\$ 7.98$ \\
Quantity & 88 & 74 & 113 & 66 & 69 & 82.00 \\
\# Permits Used & 84 & 83 & 105 & 90 & 168 & 106.00 \\
\# Permits Banked & 54 & 110 & 111 & 100 & 32 & 81.40 \\
& & & & & & \\
Trading Surplus Earned (3) & 176 & 38 & 81 & 62 & 82 & 87.80 \\
\% Trading Efficiency & $62 \%$ & $18 \%$ & $36 \%$ & $35 \%$ & $49 \%$ & $40 \%$ \\
& & & & & & \\
Units Output Produced & 724 & 683 & 935 & 811 & 1332 & 897.00 \\
\% Productive Efficiency & $93 \%$ & $88 \%$ & $99 \%$ & $98 \%$ & $94 \%$ & $94 \%$ \\
\hline
\end{tabular}


Table 8: Comparing Price Deviations and Efficiency Measures across Treatments

\begin{tabular}{|llll|}
\hline Dependent Variables & \multicolumn{1}{l}{ P-P* } & $\begin{array}{l}\text { Trading } \\
\text { Efficiency (\%) }\end{array}$ & $\begin{array}{l}\text { Productive } \\
\text { Efficiency (\%) }\end{array}$ \\
\cline { 2 - 4 } Period & 0.104 & 0.117 & 10.867 \\
& $(0.462)$ & $(0.969)$ & $(0.197)$ \\
Banking Treatment & $1.036^{\wedge}$ & -10.533 & -6.367 \\
& $(0.063)$ & $(0.244)$ & $(0.617)$ \\
Banking and Investment & 0.521 & $-37.367^{* *}$ & -47.367 \\
& $(0.261)$ & $(0.010)$ & $(0.265)$ \\
Uncertain Decline & $1.737^{* *}$ & $-41.308^{* *}$ & -3.933 \\
Constant & $(0.000)$ & $(0.000)$ & $(0.677)$ \\
& $0.889^{* *}$ & $-30.308^{* *}$ & -3.533 \\
Observations & $(0.000)$ & $(0.004)$ & $(0.724)$ \\
R-squared & -0.224 & $69.958^{* *}$ & $65.333^{* *}$ \\
& $(0.565)$ & $(0.000)$ & $(0.006)$ \\
& 26 & 26 & 26 \\
\hline & & & \\
\hline
\end{tabular}

$\wedge: \mathrm{p}<.10 ; * *: \mathrm{p}<.01$.

Trading Efficiency is calculated using the definition of Trading Surplus Earned (3).

Productive Efficiency for the Banking and Investment treatment uses the PE(2)-Act Inv.costs definition. 


\section{References}

Belanger, J. (1997). Design Proposal for Emissions Banking. Washington, DC, Ozone Transport Assessment Group: 4.

Ben-David, S., D. Brookshire, S. Burness, M. McKee and C. Schmidt. (2000). "Attitudes towards Risk and Compliance in Emission Permit Markets.” Land Economics 76(4): 590600 .

Ben-David, S., D. S. Brookshire, S. Burness, M. McKee and C. Schmidt. (1999). "Heterogeneity, Irreversible Production Choices, and Efficiency in Emissions Permit Markets.” Journal of Environmental Economics and Management 38: 176-194.

Berman, E. and L. T. Bui (1998). Environmental Regulation and Productivity: Evidence from Oil Refineries. Boston, MA, Boston University and National Bureau of Economic Research (NBER WP\#6776 November 1998): 36.

Boemare, C. and P. Quirion (2002). "Implementing Greenhouse Gas Trading in Europe: Lessons from Economic Literature and International Experiences." Ecological Economics 43(23): 213-230.

Bohi, D. R. and D. Burtraw (1992). "Utility Investment Behavior and the Emission Trading Market.” Resource and Energy 14: 129-153.

Bohm, P. (2003). Experimental Evaluations of Policy Instruments, in K. G. Maler and J. Vincent (eds), Handbook of Environmental Economics, Vol. 1 of Handbooks in Economics, Elsevier.

Bohm, P. and B. Carlen (1999). "Emission Quota Trade among the few: Laboratory Evidence of Joint Implementation among Committed Countries.” Resource and Energy Economics 21(1): 43-66.

Boyd, J., D. Burtraw, A. Krupnick, V. McConnell, R.G. Newell, K. Palmer, J.N. Sanchirico, M. Walls (2003). "Trading Cases." Environmental Science \& Technology June: 216A-213A.

Burtraw, D. (1996). "The $\mathrm{SO}_{2}$ Emissions Trading Program: Cost Savings without Allowance Trades.” Contemporary Economic Policy 14(April): 79-94.

Buckley, N., S. Mestelman and A. Muller. (2004). "Implications of Alternative Emission Trading Plans: Experimental Evidence”, mimeo, McMaster University.

Carlson, C., D. Burtraw, M. Cropper, K.L. Palmer (2000). "Sulfur Dioxide Control by Electric Utilities: What are the Gains from Trade?" Journal of Political Economy 108(6): 12921326.

Cason, T.N. and L. Gangadharan (2005). "Emissions Variability in Tradable Permit Markets with Imperfect Enforcement and Banking " forthcoming in Journal of Economic Behavior and Organization. 
Cason, T.N., S.R. Elliott, M. Van Boening (1999). "Speculation in Experimental Markets for Emissions Permits.” Research in Experimental Economics 7, C. Holt and R. M. Issac(eds). Stamford. Conn: JAI Press

Chao, H.-P. and R. Wilson (1993). “Option Value of Emissions Allowances.” Journal of Regulatory Economics 5: 233-249.

Cronshaw, M. B. and J. B. Kruse (1999). “An Experimental Analysis of Emissions Permits with Banking and the Clean Air Act Amendments of 1990.” Research in Experimental Economics 7: C. Holt and R. M. Issac(eds). Stamford. Conn: JAI Press.

Davis, D. and C. Holt. (1993). Experimental Economics, Princeton, NJ, Princeton University Press.

Dixit, A. and R. Pindyck (1993). Investment Under Uncertainty. Princeton, NJ, Princeton University Press.

Ellerman, A. D. (1996). "The Competition Between Coal and Natural Gas: The Importance of Sunk Costs.” Resources Policy 22(1/2): 33-42.

Ellerman, A.D., P. L. Joskow, R. Schmalensee, J. Montero, E. Bailey (2000) Markets for Clean Air. Cambridge: Cambridge University Press. 362.

Farrell, A. (1999). NOx Control Costs and Allowance Prices: Expectations and Outcomes. San Diego, Emissions Marketing Association Spring Meeting: 19.

Farrell, A., R. Carter, R. Raufer (1999). "The NOx Budget: Costs, Emissions, and Implementation Issues.” Resource \& Energy Economics 21(2): 103-124.

Farrell, A. E. and L. B. Lave (2004). "Emission Trading and Human Health." Annual Review of Public Health 25: 119-138.

Fichthorn, N. W. (1991). "Command-and-Control vs. the Market: The Potential Effects of Other Clean Air Act Requirements on Acid Rain Compliance.” Environmental Law 21: 20222084.

Foster, V. and R. W. Hahn (1995). "Designing More Efficient Markets: Lessons From Los Angeles Smog Control.” Journal of Law and Economics 38(1): 19-48.

Fullerton, D., S. McDermott, J.P. Caulkins. (1997). "Sulfur Dioxide Compliance of a Regulated Utility.” Journal of Environmental Economics and Management 34(1): 32-53.

Godby, R., S. Mestelman, R.A. Muller, D. Welland. (1997). "Emissions Trading with Shares and Coupons when Control over Discharges is Uncertain.” Journal of Environmental Economics and Management 32(3): 359-381. 
Godby, R., S. Mestelman, R.A. Muller, D. Welland. (1998). "An Experimental Economic Analysis of Emissions Trading with Shares and Coupons in the Presence of Market Uncertainty.” Environmetrics 9(1): 67-79.

Godby, R. (1999), "Market Power in Emission Permit Double Auctions," in Research in Experimental Economics, vol. 7, C. Holt and R. M. Isaac (eds.), Stamford, Conn.: JAI Press, pp. 121-162.

Hahn, R. (1989). "Economic Prescriptions for Environmental Problems: How the Patient Followed the Doctor's Orders.” Journal of Economic Perspectives 3(2): 95-114.

Hindsberger, M., M.H. Nybroe, H.F. Ravn, R. Schmidt (2003). "Co-existence of electricity, TEP, and TGC markets in the Baltic Sea Region." Energy Policy 31(1): 85-96.

Hoffert, M.I., K. Caldeira, G. Benford, D.R. Criswell, C. Green, H. Herzog, J.W. Katzenberger, H.S. Kheshgi, K.S. Lackner, J.S. Lewis, W. Manheimer, J.C. Mankins, G. Marland, M.E. Mauel, L.J. Perkins, M.E. Schlesinger, T. Volk, and T.M.L. Wigley (2002). "Advanced Technology Paths to Global Climate Stability: Energy for a Greenhouse Planet." Science 298: 981-987.

Holt, C. (1995). Industrial Organization: A Survey of Laboratory Results. Handbook of Experimental Economics. J. Kagel and A. Roth. Princeton, NJ, Princeton University Press: 349-435.

Kagel, J. H. and A. E. Roth. (1995). The Handbook of Experimental Economics. Princeton, NJ, Princeton University Press.

Klier, T.H., R.H. Mattoon, M.A. Prager. (1997). "What can the Midwest learn from California about Emissions Trading?” Chicago Fed Letter: 3.

Kling, C. and J. Rubin (1997). "Bankable Permits for the Control of Environmental Pollution.” Journal of Public Economics 64(1): 101-115.

Kusakawa, T. and T. Saijo (2003). "Emissions Trading Experiments: Investment Uncertainty and Liability” Manuscript, Osaka University.

Lents, J. M. and P. Leyden (1996). "RECLAIM: Los Angeles' New Market-Based Smog Cleanup Program.” Journal of the Air \& Waste Management Association 46: 195-206.

Mestelman, S., R. Moir and R. A. Muller (1999). “A Laboratory Test of a Canadian Proposal for an Emissions Trading Program.” Research in Experimental Economics 7: C. Holt and R. M. Issac(eds). Stamford. Conn: JAI Press.

Montero, J.-P. and A. D. Ellerman (1998). Explaining Low Sulfur Dioxide Allowance Prices: The Effects of Expectation Errors and Irreversibility. Cambridge, MA, MIT Center for Energy and Environmental Research: 23. 
Muller, R. A. and S. Mestelman (1998). "What Have We Learnced from Emissions Trading Experiments ?” Managerial and Decision Economics 19: 225-238.

Murphy, J. and J. Stranlund (2004) Direct and Market Effects of Enforcing Emissions Trading Programs: An Experimental Analysis. Mimeo, University of Massachusetts-Amherst.

Plott, C. R. (1983). "Externalities and Corrective Policies in Experimental Markets.” Economic Journal 93: 106-127.

Plott, C. R. and D. P. Porter (1996). "Market Architectures and Institutional Testbedding: An Experiment with Space Station Pricing Policies." Journal of Economic Behavior \& Organization 31(2): 237-272.

Rubin, J. D. (1996). “A Model of Intertemporal Emission Trading, Banking, and Borrowing.” Journal of Environmental Economics and Management 31(3): 269-286.

Smith, V. L. (1962). “An Experimental Study of Competitive Market Behavior.” Journal of Political Economy 70: 111-137.

Smith, V. L. and A. W. Williams (1992). "Experimental Market Economics." Scientific American. 267: 116-122.

Winebrake, J., A. Farrell, M.A. Bernstein. (1995). "The Clean Air Act's Sulfur Dioxide Emissions Market: Estimating the Costs of Regulatory and Legislative Intervention.” Resource and Energy Economics 17(3): 239-260. 


\section{Appendix A: Optimal Investment Decisions}

Claim: in equilibrium only type 4 invests, types 1,2 and 3 do not invest and produce (as much as possible) while types $5 \& 6$ do not invest and sell their permits.

This yields the following market characteristics for a market with one of each type of firm.

1 firm who was type 4 , now type 0 , with permit value of $\$ 10$,capacity of 8 permits and endowment of 4 permits

1 firm of type 1 with permit value of \$10, capacity of 5 permits and endowment of 1 permit 1 firm of type 2 with permit value of $\$ 9$, capacity of 7 permits and endowment of 2 permits 1 firm of type 3 with permit value of $\$ 8$, capacity of 9 permits and endowment of 3 permits 1 firm of type 5 with permit value of $\$ 6$, capacity of 13 permits and endowment of 5 permits 1 firm of type 6 with permit value of $\$ 5$, capacity of 15 permits and endowment of 6 permits

The supply and demand for permits is thus now:

$\begin{array}{lll}\text { Price } & \text { Demand } & \text { Supply } \\ 10 & 8 & 16 \\ 9 & 13 & 14 \\ 8 & 19 & 11 \\ 7 & 19 & 11 \\ 6 & 27 & 6 \\ 5 & 38 & 0\end{array}$

The equilibrium prediction is thus that permits sell for between \$8 and \$9 in each period.

Now we check for deviations from this proposed equilibrium.

First, type 1 does not want to invest. If type 1 invests, even if his investment left the market price unchanged, his profits would increase from $\$ 18$ (buying 4 permits at $\$ 8$ and using them plus his 1 endowment to generate 5 units of electricity worth \$10) to \$23 (buying 4 permits at $\$ 8$ and using them plus his one endowment to generate 5 units of electricity worth \$11). Thus investing earns an extra \$5 per period, over an expected 5 periods not enough to recoup the fixed cost of $\$ 80$.

Second, type 2 does not want to invest for the same reason. If type 2 invests, even if his investment left the market price unchanged, his profits increase from $\$ 23$ (buying 5 permits at $\$ 8$ and using them plus his 2 endowment to generate 7 units of electricity worth $\$ 9$ ) to $\$ 34$ (buying 4 permits at $\$ 8$ and using them plus his 2 endowment to generate 6 units of electricity worth $\$ 11$ ). Thus investing earns an extra $\$ 11$ per period, over an expected 5 periods not enough to recoup the fixed cost of $\$ 80$

Third, type 3 does not want to invest. If he invests the price increases to $\$ 9$ per unit, thus his profits increase from $\$ 24$ (buying 6 permits at $\$ 8$ and using them plus his 3 endowment to generate 9 units of electricity worth $\$ 8$ ) to $\$ 34$ (buying 4 permits at $\$ 9$ and using them plus his 3 endowment to generate 7 units of electricity worth $\$ 10$ ). Thus investing earns 
an extra $\$ 10$ per period, over an expected 5 periods is not enough to recoup the fixed cost of $\$ 80$.

Fourth, type 4 does not want to reverse his investment. If he does so, the price remains at 8 , but his profits decrease from \$48 per period (8 units produced at \$10 per unit minus 4 units bought at $\$ 8$ per unit) to $\$ 21$ per period (11 units produced at $\$ 7$ per unit minus 7 units bought at $\$ 8$ per unit). Over an expected 5 periods he thus loses $\$ 135$; significantly more than the $\$ 80$ investment cost.

Fifthly, type 5 does not want to invest. Type 5 was selling his 5 permits at $\$ 8$ earning $\$ 40$ per period. If he invests the price increases to $\$ 9$ per unit and he becomes a net buyer of permits, buying 4 permits at $\$ 9$ and producing with those plus his endowed 5 permits, earning \$9 times 9 permits, $\$ 81$ per period minus $\$ 36$ for purchasing the permits $=\$ 45$ per period Thus type 5 earns an extra $\$ 5$ per period for investing, over an expected 5 periods; not enough to recoup the fixed cost of $\$ 80$.

Finally, type 6 does not want to invest. Type 6 was selling his 6 permits at $\$ 8$ earning $\$ 48$ per period. If he invests, the price increases to $\$ 9$ per unit and he becomes a net buyer of permits, buying 2 permits at $\$ 9$ and producing with those plus his endowed 6 permits, earning \$9 times 8 permits, \$72 minus \$18 for permit purchases $=\$ 54$ per period. Thus type 6 earns an extra $\$ 6$ per period for investing, over an expected 5 periods not enough to recoup the fixed cost of $\$ 80$. 


\section{University Library}

\section{- M M I E E R VA A gateway to Melbourne's research publications}

Minerva Access is the Institutional Repository of The University of Melbourne

Author/s:

GANGADHARAN, LATA;Farrell, Alex;Croson, Rachel

Title:

Investment decisions and emissions reductions: results from experiments in emissions trading

Date:

2005-07

Citation:

Gangadharan, Lata and Farrell, Alex and Croson, Rachel (2005) Investment decisions and emissions reductions: results from experiments in emissions trading.

Persistent Link:

http://hdl.handle.net/11343/34183 